\title{
Changes In The Radioactivity, Topography, And Surface Composition Of Uranium After Hydrogen Loading By Aqueous Electrolysis
}

\author{
J.Dash \\ Low Energy Nuclear Laboratory, Portland State University, Portland, Oregon, U.S.A., dashj@pdx.edu \\ D. Chicea \\ Physics Department, University Lucian Blaga of Sibiu,Romania \\ dan.chicea@ulbsibiu.ro
}

\begin{abstract}
Hydrogen loading of $99.98 \%$ pure natural uranium foils $(0.18 \mathrm{~mm}$ thick) was performed by aqueous electrolysis in order to compare with glow discharge results. Alpha, beta, and gamma specific radioactivity were measured after hydrogen loading and compared with the control. Some of the samples revealed an increase of the specific radioactivity of up to $20 \%$. Gamma ray spectroscopy was also performed on the samples. Results reveal an increase of the specific counts for the peaks of Th234 and U235 and a decrease in the U $\mathrm{K} \alpha 1$ characteristic $\mathrm{x}$-ray peak. The surface topography changed from granular before electrolysis to pitted afterward. The thorium concentration increased slightly after electrolysis compared with the original material. In summary, this work in progress reveals that loading hydrogen into uranium increases the uranium decay rate, in agreement with the glow discharge results.
\end{abstract}

\section{Introduction}

This paper describes five experiments that were performed to load hydrogen into natural (not enriched) metallic uranium samples. All samples were taken from the same batch. One sample randomly selected was considered the reference (control) sample and the other five were loaded with hydrogen. The electrolysis parameters are presented in the next section. Non-spectrometric alpha, beta and gamma radioactivity of each sample was measured using a Ludlum Model 3030 alpha-beta counter, and gamma ray spectra were recorded using an ORTEC gamma ray spectrometer. The results of the alpha, beta and gamma counting are presented in section 3 . The results of the gamma ray spectrometry are presented in section 4 , and the changes in topography and surface composition are given in section 5. These results are discussed in section 6.

\section{Hydrogen loading parameters}

The cathode was natural uranium foil, $0.18 \mathrm{~mm}$ thick, of purity $99.98 \%$. It was obtained from Goodfellow Corp. The electrolyte was $\mathrm{H}_{2} \mathrm{SO}_{4}$, in deionized $\mathrm{H}_{2} \mathrm{O}$. For $\mathrm{S} 2$, DC1 and DC2 the $\mathrm{H}_{2} \mathrm{SO}_{4}$ which was used was obtained from Alfa Aesar, Stock number 11000, Lot B05119, and the electrolyte was 0.83M. For experiments with cathodes DC3 and DC4 the $\mathrm{H}_{2} \mathrm{SO}_{4}$ was obtained from J.T. Baker, lot K10030 and the electrolyte was $0.74 \mathrm{M}$. The anode was made of platinum foil, $0.1 \mathrm{~mm}$ thick, $99.99 \%$ purity (metal basis), Lot Number: 09119EU, obtained from the Aldrich Co. It was a circular platinum disc under the cathode for S2, DC1 and DC2, and had the shape presented in Fig. 1 for DC3 and DC4.

The uranium cathode foil was pierced and the platinum cathode lead wire was bent to make a small hook which is then crimped against the uranium foil. After attaching the cathode to the cathode holder, the electrical contacts for samples DC2, DC3, and DC4 were insulated with 732 Multi-Purpose Silicone Sealant, 
( $100 \%$ silicone rubber), to minimize electrolyte contact with the U-Pt contact. With this design the U-Pt contact corrosion was minimized, thus enabling prolonged electrolysis.

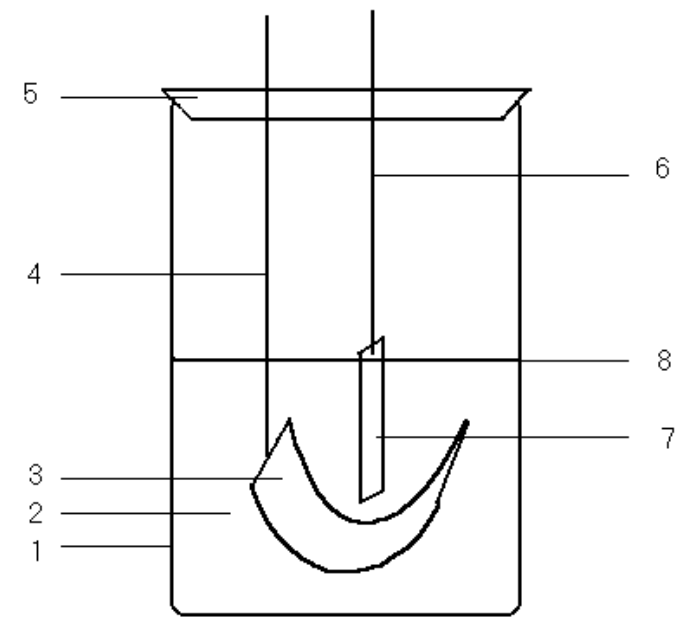

The cell design is presented in Fig. 1 where the numbers represent:

1. Beaker (200 ml, Pyrex)

2. Electrolyte

3. Pt Anode

4. Anode Pt holder

5. Teflon cap

6. Pt cathode holder

7. Uranium foil cathode

8. Electrolyte level

With this cell five experiments were conducted. Experiments labelled as S2 and DC1 did not have insulation covering the electric contact between the platinum cathode lead wire and the cathode, while DC2, 3 and 4 had the electrical contact insulated. The electrolysis parameters are summarized below.

Table 1. Current, voltage, current density and electrolysis time for the five experiments.

\begin{tabular}{|c|c|c|c|c|}
\hline Experiment & Current, A & Voltage, $\mathrm{V}$ & Current density, $\mathrm{mA} / \mathrm{cm}^{2}$ & Electrolysis time, $\mathrm{h}$ \\
\hline $\mathrm{S} 2$ & 1.5 & 4.0 & 1781 & 5 \\
\hline $\mathrm{DC} 1$ & 0.075 & 3.0 & 50 & 72 \\
\hline $\mathrm{DC} 2$ & 0.4 & 2.9 & 370 & 206 \\
\hline $\mathrm{DC} 3$ & 0.035 & 2.4 & 26 & 65 \\
\hline DC4 & 0.15 & 2.5 & 54 & 66 \\
\hline
\end{tabular}

\section{Non - spectrometric alpha, beta, and gamma radioactivity measurement}

The samples were weighed and radioactivity was measured with a Ludlum Model 3030 Alpha-Beta Sample Counter, having an organic scintillator in a shielded chamber and a pulse-height analyzer that provides information to two independent counters. The counter has a RS232 interface that enables data acquisition and operating parameters control and adjustment using a PC. The counter was used in the scaler mode. The count accuracy of the detection system is $2 \%$, as stated by the manufacturer.

Each sample was weighed before and after the experiment using a Mettler model H70 balance. After that the samples were cut in such a manner that the parts that were above the electrolyte level were separated from the parts that were below the electrolyte level. The parts that were above were labeled with a trailing P1a 
while those that were under the electrolyte during the experiment were labeled with a trailing $\mathrm{P} 2 \mathrm{u}$. In addition to the $\alpha$ and $\beta$ counts that the Ludlum Model 3030 counter provides, $\gamma$ radioactivity was measured as well. In order to do a $\gamma$ radioactivity measurement the sample was completely covered with an aluminum plate $0.9 \mathrm{~mm}$ thick. The aluminum plate completely absorbed $\alpha$ particles and statistically almost all of the $\beta$ particles. Therefore the counts on the $\beta$ channel with the aluminum plate between sample and detector are proportional to the $\gamma$ activity of the sample.

For each sample the background on both alpha and beta channels was measured before the counting and was subsequently subtracted, and the specific radioactivity, that is counts per second per gram, was calculated. The results of the measurements performed with the Ludlum counter for the two parts of the sample are presented in Table 2. Variation is defined as electrolyzed sample radiation minus control sample radiation divided by control radiation.

Table 2. Alpha, beta and gamma radiation and variation for the five samples and control

\begin{tabular}{|c|c|c|c|c|c|c|}
\hline Sample & $\begin{array}{c}\text { Specific } \\
\text { alpha, } \\
\mathrm{c} / \mathrm{g} * \mathrm{~s}\end{array}$ & $\begin{array}{c}\text { Alpha } \\
\text { variation, } \\
\%\end{array}$ & $\begin{array}{c}\text { Specific } \\
\text { beta, } \\
\mathrm{c} / \mathrm{g} * \mathrm{~s}\end{array}$ & $\begin{array}{c}\text { Beta } \\
\text { variation, } \\
\%\end{array}$ & $\begin{array}{c}\text { Specific } \\
\text { gamma, } \\
\mathrm{c} / \mathrm{g}{ }^{\mathrm{s}}\end{array}$ & $\begin{array}{c}\text { Gamma } \\
\text { variation, } \\
\%\end{array}$ \\
\hline S1 & 97 & & 2210 & & 545 & \\
\hline S2P1a & 142 & 47.2 & 2711 & 22.7 & 640.7 & 17.5 \\
\hline S2P2u & 115 & 19 & 2470 & 11.8 & 595 & 9.1 \\
\hline DC1P1a & 158 & 63.4 & 2726 & 23.4 & 660 & 21 \\
\hline DC1P2u & 124 & 28.7 & 2354 & 6.5 & 580 & 6.3 \\
\hline DC2P1a & 107 & 11.1 & 2338 & 5.8 & 581 & 6.5 \\
\hline DC2P2u & 128 & 33.1 & 2542 & 15 & 617 & 13.1 \\
\hline DC3P1a & 115 & 19.5 & 2345 & 6.1 & 583 & 6.9 \\
\hline DC3P2u & 110 & 13.9 & 2514 & 13.8 & 599 & 9.8 \\
\hline DC4P1a & 115 & 19 & 2407 & 8.9 & 543 & -0.5 \\
\hline DC4P2u & 120 & 24.8 & 2317 & 4.9 & 576 & 5.6 \\
\hline
\end{tabular}

The data presented in Table 2 is plotted in Figures 2 and 3. Examining Table 2 and Figures 2 and 3, we notice that alpha variation is bigger than beta, and beta is bigger than gamma variation. We also notice that for sample S2 and DC1 (no insulation on cathode contact), the part that was above the electrolyte has a bigger increase of the specific radioactivity for all the three types of radioactivity than the part that was under electrolyte, while for the samples DC2 through DC4 (insulated cathode contact) the results show the opposite.

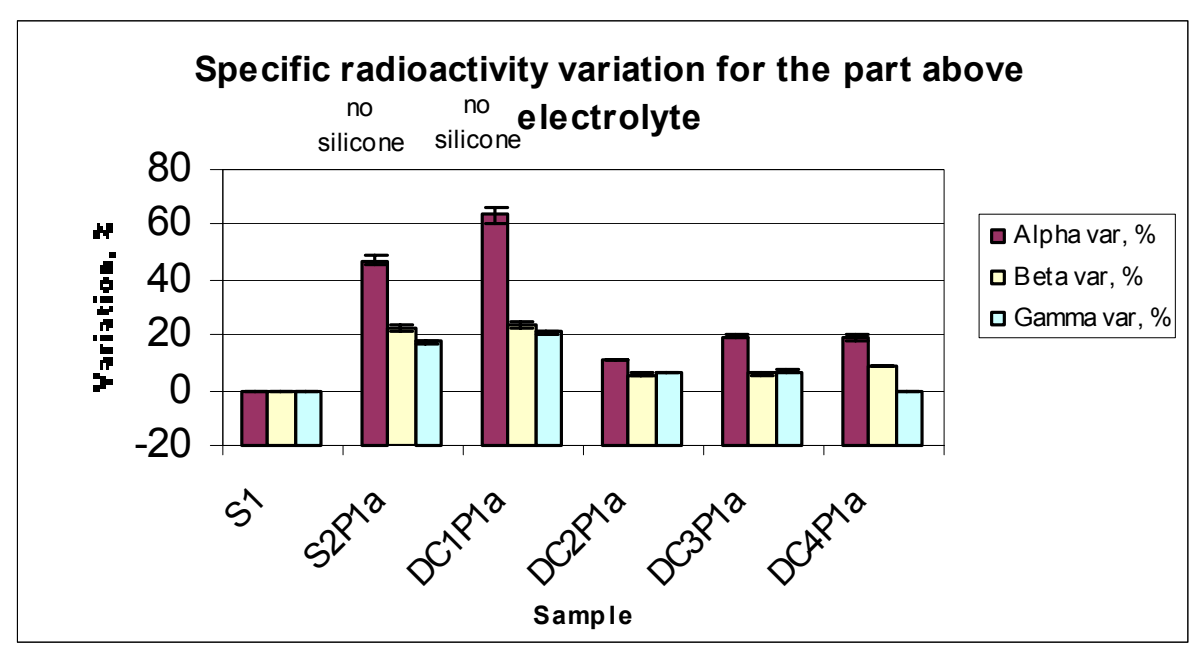

Fig. 2. The variation of the specific alpha, beta and gamma radioactivity of the part that was above electrolyte, compared with the reference sample $\mathrm{S} 1$. 


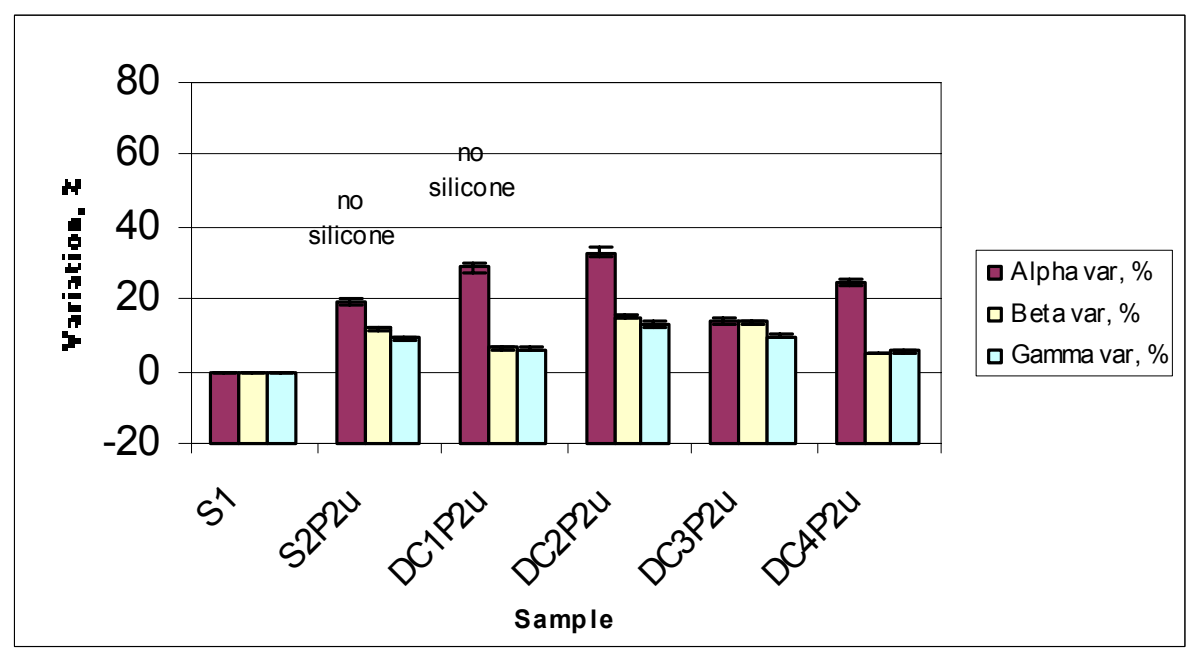

Fig. 3. The variation of the specific alpha, beta and gamma radioactivity of the part that was under electrolyte, compared with the reference sample $\mathrm{S} 1$.

\section{Gamma ray spectroscopy results}

The gamma spectra were acquired using an ORTEC gamma ray spectrometer with 8000 channels and a germanium detector cooled to liquid nitrogen temperature. The spectra were analyzed with Gammavission-32 software. Each sample was placed in a plastic dish and counted for one hour on each of the sides, and the data was averaged. The data averaged for the two sides of each part of each sample, divided by the mass, therefore expressed in gamma counts per gram - hour, are presented in Tables 3 and 4.

Table 3. Specific (counts per gram-hour) gamma and characteristic $x$-ray data for control and for the portions of the samples above electrolyte.

\begin{tabular}{|c|c|c|c|c|c|c|}
\hline Line / Sample & S1 & S2P1a & DC1P1a & DC2P1a & DC3P1a & DC4P1a \\
\hline $92.4 \mathrm{keV} \mathrm{Th234}$ & 276898 & 302659 & 300854 & 277542 & 270147 & 268015 \\
\hline $98.5 \mathrm{keV}$ U Ka1 & 131785 & 122452 & 119314 & 128507 & 129092 & 131300 \\
\hline $186 \mathrm{keV} \mathrm{U235}$ & 108863 & 118427 & 116934 & 109603 & 106548 & 108958 \\
\hline
\end{tabular}

Table 4. Specific (counts per gram-hour) gamma and characteristic x-ray data for control and for the portions of the samples below electrolyte.

\begin{tabular}{|c|c|c|c|c|c|c|}
\hline Line/Sample & S1 & S2P2u & DC1P2u & DC2P2u & DC3P2u & DC4P2u \\
\hline $92.4 \mathrm{keV} \mathrm{Th234}$ & 276898 & 288293 & 288892 & 295887 & 291973 & 274560 \\
\hline $98.5 \mathrm{keV} \mathrm{U} \mathrm{K \alpha 1}$ & 131785 & 127667 & 132771 & 128026 & 126001 & 129023 \\
\hline $186 \mathrm{keV} \mathrm{U235}$ & 108863 & 112547 & 114350 & 116630 & 113957 & 109334 \\
\hline
\end{tabular}

Among the gamma lines and the characteristic $\mathrm{x}$-ray lines, the $\mathrm{Th}^{234} 92.4 \mathrm{keV}$ gamma line, $\mathrm{U} 98.5 \mathrm{keV}$ $\mathrm{K} \alpha 1 \mathrm{x}$-ray, and $\mathrm{U}^{235} 186 \mathrm{keV}$ gamma line counts are measured with the smallest error. Therefore, they were selected to be presented. The plots of specific counts for the samples, measured separately for the part that was above electrolyte or under electrolyte, expressed in counts/gram*hour, are presented in Figures 4 through 6. 


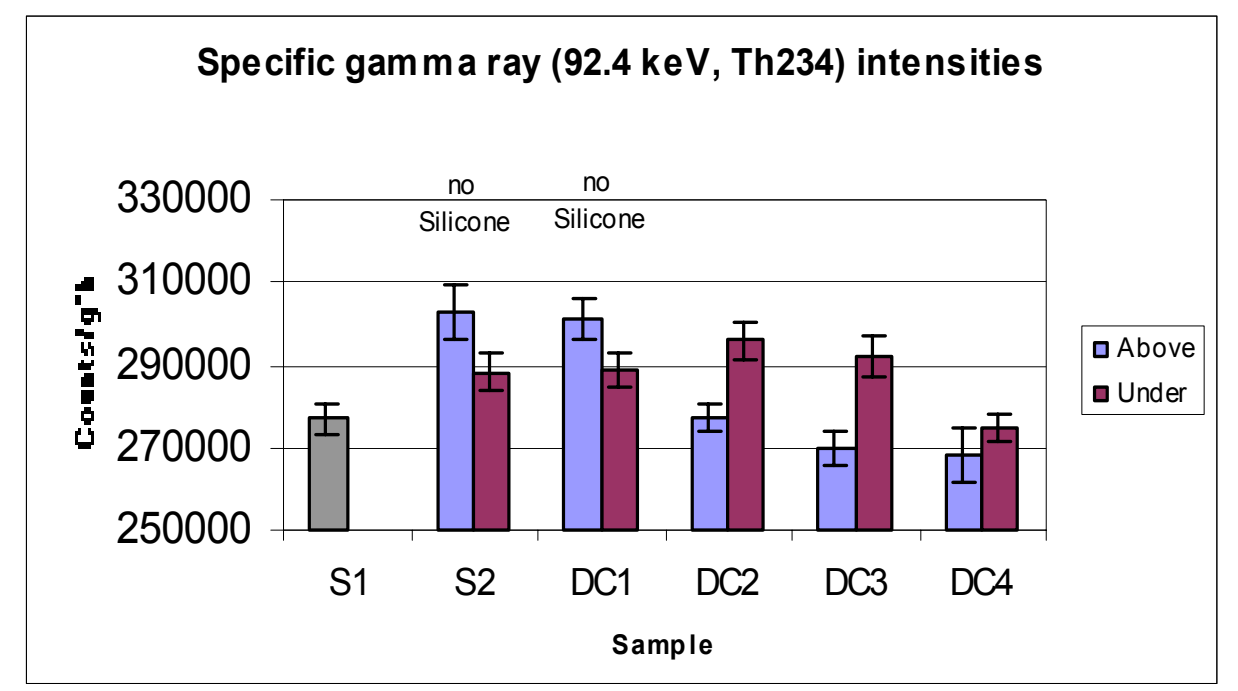

Fig. 4. $92.4 \mathrm{Th}^{234} \mathrm{keV}$ gamma ray specific intensity for the electrolysed uranium samples compared with the control

Examining Figure 4 we notice that for S2 and DC1, hydrogen loading produced a significant increase of the specific $92.4 \mathrm{Th}^{234} \mathrm{keV}$ gamma ray emission and for the other three samples the variation is within the experimental error, for the parts of the samples above electrolyte. Four of the parts that were under direct hydrogen exposure, that is under electrolyte, present a significant increase of the specific $92.4 \mathrm{Th}^{234} \mathrm{keV}$ gamma ray emission while one (DC4) has no significant variation.

Figure 5 shows that both parts of samples S2, DC2, and DC3 present a decrease of the $98.5 \mathrm{keV}$ uranium K $\alpha 1$ characteristic $\mathrm{x}$-ray specific counts. The portion of DC1 above the electrolyte level has about 10\% lower intensity than the control, but the portion below has the same intensity as the control. Both parts of DC4 have about the same intensity as the control. Figure 6 reveals that $\mathrm{U}^{235}$ gamma ray specific radioactivity increased as a result of hydrogen loading for both parts of S2 and DC1 and for the parts of DC2 and DC3 which were below the electrolyte level. It was not modified for DC4.

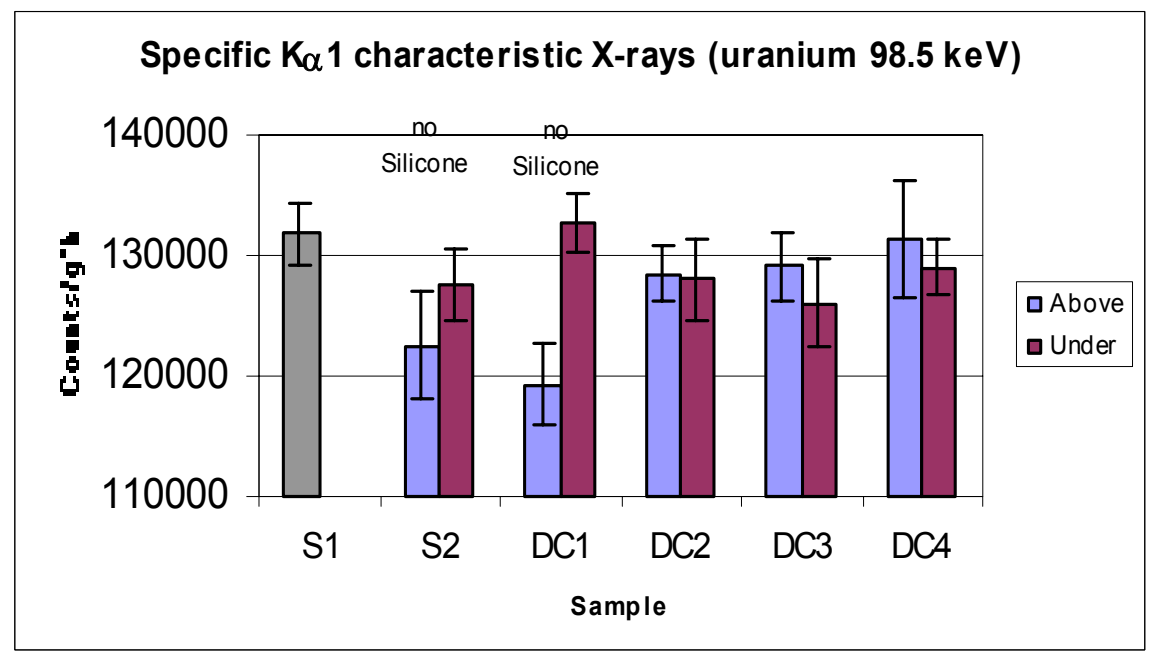

Fig. 5. Kal $98.5 \mathrm{keV}$ uranium characteristic $x$-ray specific intensity for the electrolyzed uranium samples compared with the control 


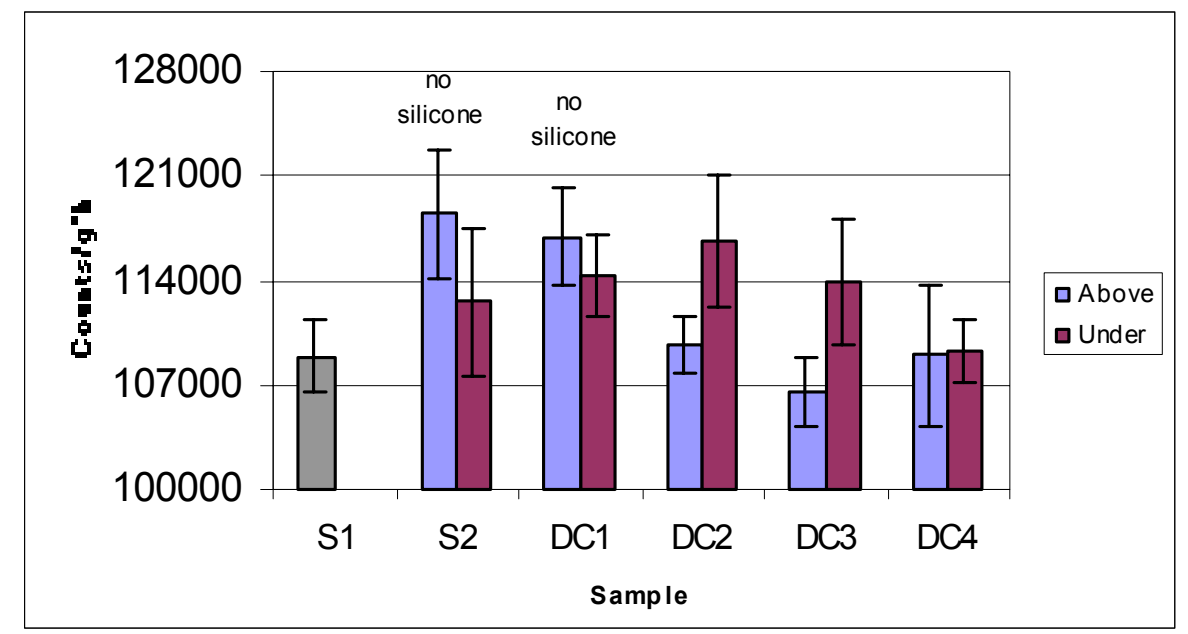

Fig. 6. $186 \mathrm{keV} U^{235}$ gamma ray specific intensity for the electrolysed uranium samples compared with the control (S1).

\section{Topography and surface composition}

Changes in surface morphology which resulted from electrolysis were determined with a scanning electron microscope (SEM), and changes in surface chemical composition were determined with an energy dispersive spectrometer (EDS) attached to the SEM.

A typical image of the natural uranium surface before electrolysis is presented in Fig. 7. The surface is nonuniformly fissured and granulated, with granule sizes up to 3-4 $\mu \mathrm{m}$.

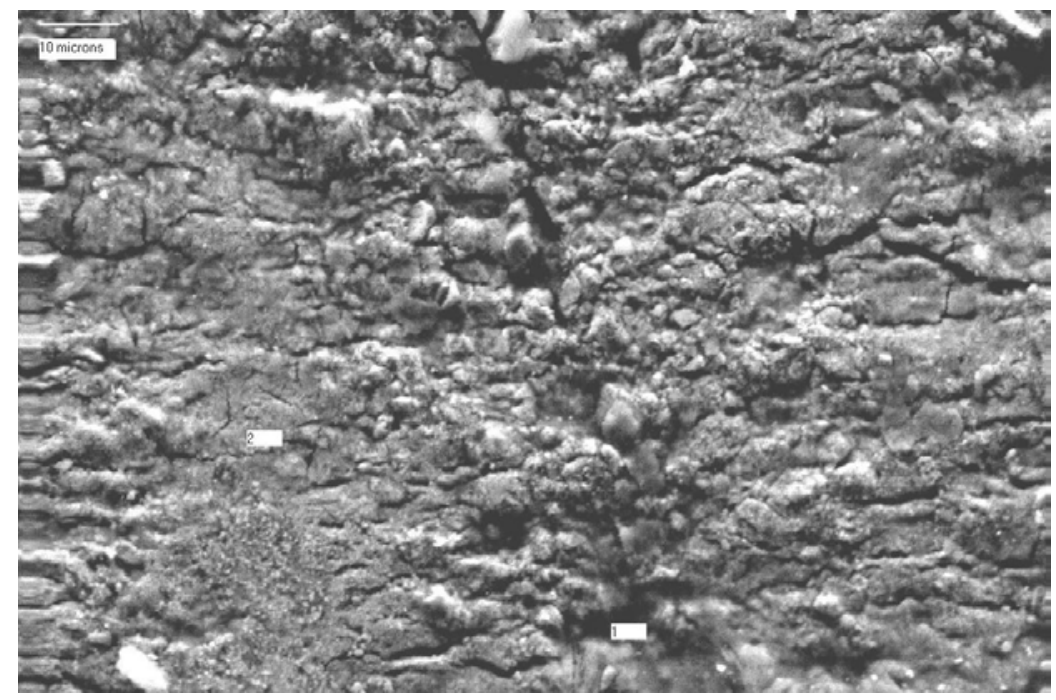

Fig. 7. Magnified image of the unelectrolyzed natural uranium surface magnified image of the unelectrolyzed natural uranium 
Sample DC1 was electrolyzed and analyzed following the same procedure, that is taking a low magnification image first, then high magnification images and spectra from several locations. A magnified image of the surface of sample DC1, after absorbing hydrogen, is presented in Fig. 8. Sample DC1 presents evidence of pitting, which may have been caused by the formation of uranium hydride and erosion. The surface is covered with pits having a typical size of about $1 \mu \mathrm{m}$. The main difference in the topography of the surface is that on the unelectrolyzed natural uranium sample surface the granules protrude above the surface while on the electrolysed sample the surface is pitted.

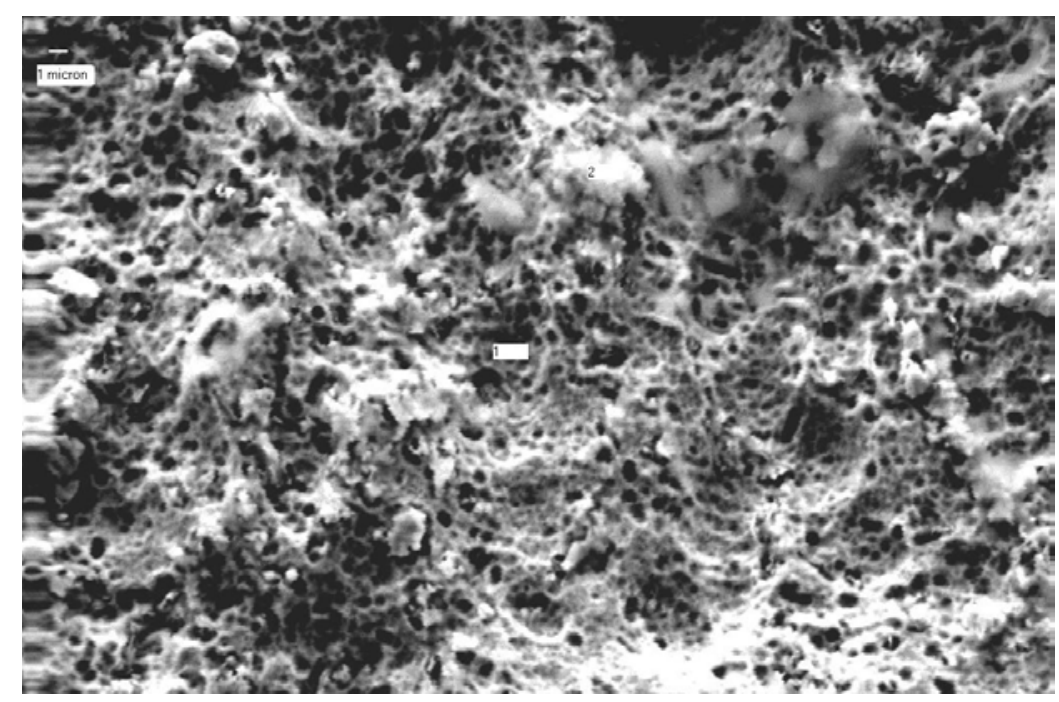

Fig. 8. A magnified image of the DC1 uranium surface after hydrogen loading by electrolysis.

The concentrations of thorium and carbon were measured on an as-received natural uranium sample (the control) and on each sample after electrolytic loading with hydrogen. The concentration data were obtained with an Oxford Model 5565 EDS, attached to an ISI Model SS40 SEM. The data presented in the tables and the standard deviations, hereafter sigma, are atomic concentrations.

First only thorium and uranium were selected on the list for the quantitative analysis. Table 5 presents the average values of thorium concentrations and the average standard deviations $(\sigma)$.

Table 5. Average thorium concentration and standard deviation for the control natural uranium sample (S1) and for the samples that were loaded with hydrogen.

\begin{tabular}{|c|c|c|c|c|}
\hline Sample & Th (\%) & $\sigma$ Th (\%) & Number of spectra & $\begin{array}{c}\text { Average counts for } \\
\text { each spectrum }\end{array}$ \\
\hline S1( control) & 0.96 & 0.43 & 14 & 480321 \\
\hline DC1 & 1.05 & 0.37 & 13 & 537439 \\
\hline DC2 & 1.24 & 0.43 & 13 & 522777 \\
\hline DC3 & 1.95 & 0.68 & 10 & 180598 \\
\hline DC4 & 1.56 & 0.63 & 23 & 583748 \\
\hline
\end{tabular}

The averages are calculated for each sample separately. Table 5 shows that there is an increase of the thorium concentration for the hydrogen-loaded uranium samples compared with the control, but the increase is smaller than one sigma. All of the thorium concentrations in Table 5 exceed two standard deviations, so the results are significant.

The carbon concentrations on the sample surfaces were also determined by EDS. Table 6 presents the average values of the surface carbon content and the average standard deviations for each sample. Examining Table 6, we notice first that the carbon concentrations are significantly larger than two standard deviations. All 
of the electrolysed samples have significantly less carbon than the unelectrolyzed control. The origin of this carbon is not known.

Table 6. Carbon average concentrations and standard deviations for the control natural uranium sample (S1) and for the samples that were loaded with hydrogen.

\begin{tabular}{|c|c|c|c|c|}
\hline Sample & $\mathrm{C} \mathrm{( \% )}$ & $\sigma \mathrm{C}(\%)$ & Number of spectra & Average counts \\
\hline S1 ( control) & 59.79 & 0.88 & 13 & 775233 \\
\hline DC1 & 51.28 & 0.81 & 15 & 469438 \\
\hline DC2 & 42.76 & 0.56 & 16 & 500043 \\
\hline DC3 & 32.54 & 0.71 & 11 & 187373 \\
\hline DC4 & 34.57 & 0.93 & 23 & 583748 \\
\hline
\end{tabular}

The data presented in Tables 5 and 6 is plotted in Figures 9 and 10, respectively.

When examining the Tables 5 and 6 , we should be aware that the concentrations that are written on the SEM analysis sheet are not the absolute concentrations. For example, $1 \%$ Th means that the ratio $\mathrm{Th} / \mathrm{U}$ is $1 / 99$, and $50 \% \mathrm{C}$ means that the ratio $\mathrm{C} / \mathrm{U}$ is $50 / 50$, etc. Another important point is that the EDS analysis gives the composition of the surface to a depth of about $1 \mu \mathrm{m}$, since a $20 \mathrm{keV}$ electron beam is used.

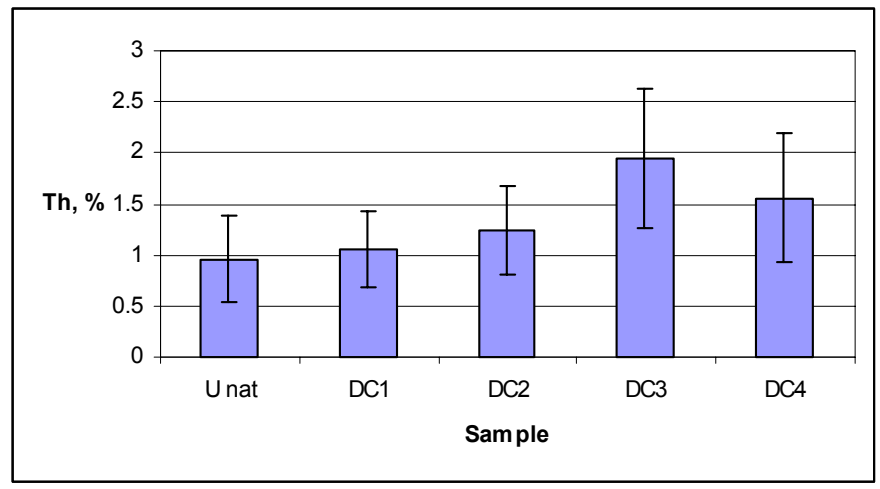

Fig. 9. Thorium concentration for electrolyzed samples compared with the control (Unat).

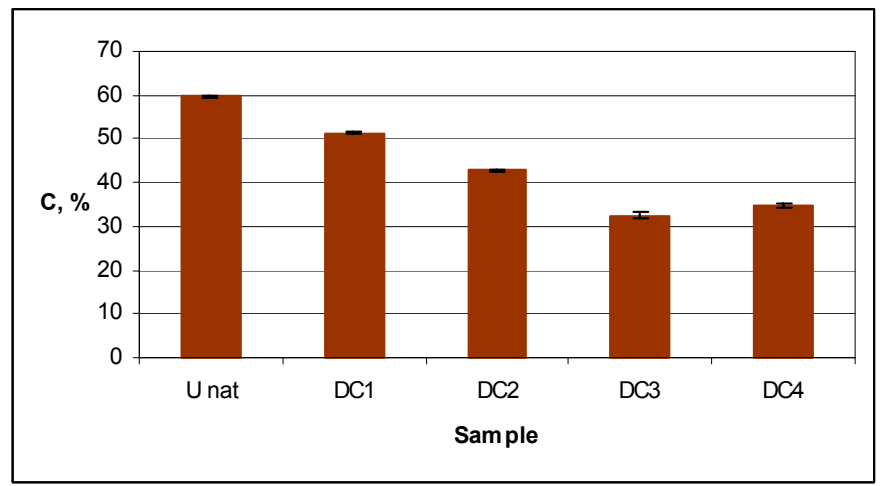

Fig. 10. Surface carbon concentration for the electrolyzed samples compared with the control,Unat contro 


\section{Discussion}

The results of the experiments of loading hydrogen into natural uranium samples using electrolysis reveal that the intensity of the alpha radioactivity of the samples increased after loading hydrogen, both for the parts that were located under electrolyte and above electrolyte. The same result was found for the beta radioactivity. The gamma radioactivity increased for the parts of the samples that were under electrolyte for all the samples and for the parts that were above electrolyte for four out of five samples, and was not modified for one of the samples. These results show with a precision that is well above the experimental errors that the alpha, beta and gamma radioactivity of the natural uranium samples increased as a result of absorbing hydrogen.

Gamma ray spectrometry revealed that for the majority of the samples the intensity of the $92.4 \mathrm{keV}$ $\mathrm{Th}^{234}$ gamma line increased, the intensity of the $186 \mathrm{keV} \mathrm{U}{ }^{235}$ increased and the intensity of the $98.5 \mathrm{keV}$ uranium K $\alpha$ lcharacteristic $\mathrm{x}$-ray peak decreased. The atomic electron excitations are produced primarily by the alpha particles emitted by $\mathrm{U}^{238}$ decay. The alpha emission proved to be more intense but the uranium characteristic X-ray intensity decreased. This suggests that the uranium concentration in the electrolyzed sample decreased while the $\mathrm{U}^{235}$ and $\mathrm{Th}^{234}$ concentrations increased. $\mathrm{Th}^{234}$ follows $\mathrm{U}^{238}$ directly in the $\mathrm{U}^{238}$ decay chain, as presented in equation 1 . The half life is 24.10 days [1]. The increase of $\mathrm{Th}^{234}$ concentration suggests that the $\mathrm{U}^{238}$ decay rate has been increased as a result of hydrogen absorption.

$$
{ }_{92} U^{238} \stackrel{4.468 \mathrm{E}+9 \mathrm{y}}{\longrightarrow}{ }_{90} T h^{234}
$$

A set of nuclear reactions that might explain the increase of the $\mathrm{U}^{235}$ concentration, under the assumption that the decay rate stated in equation 5 is increased, might be:

$$
\begin{gathered}
{ }_{92} U^{238}+n \rightarrow{ }_{92} U^{239} \\
{ }_{92} U^{239} \stackrel{\beta^{-}, T_{1 / 2}=23.45 m}{\longrightarrow}{ }_{93} N p^{239} \\
{ }_{93} N p^{239} \stackrel{\beta^{-}, T_{1 / 2}=2.3565 d}{\longrightarrow}{ }_{94} P u^{239} \\
{ }_{94} P u^{239} \stackrel{\alpha, T_{1 / 2}=24110 y}{\longrightarrow}{ }_{92} U^{235}
\end{gathered}
$$

The half life of the isotopes in equations 2 through 5 are taken from [2 - 6]. The nuclear reaction in equation (2) is suggested in [7] and the reaction mechanism in [8].

These results are very similar to those reported in [9] and [10] where the gamma ray spectrometry and thermal ionization mass spectrometry results reveal a $1 \%$ decrease of the uranium concentration in the samples that were exposed to hydrogen isotope plasma. In order to verify that the $\mathrm{U}^{238}$ half life has been decreased, measurements must be taken periodically over a time interval of years to check whether the alpha radioactivity remains increased and whether the $\mathrm{Th}^{234}$ gamma activity remains higher than for the reference sample. Another way to verify that the $\mathrm{U}^{238}$ decay rate has increased for all the isotopes in the $\mathrm{U}^{238}$ decay chain would be to measure the $\mathrm{Pb}^{206}$ to $\mathrm{Pb}^{204}$ ratio by mass spectrometry in both the electrolysed samples and the reference sample. If it is higher in the electrolyzed sample than in the reference sample, then the whole $\mathrm{U}^{238}$ chain decay rate has been increased by hydrogen absorption. This result was already obtained for uranium exposed to hydrogen isotope plasmas [10].

\section{Acknowledgement}

This research was supported by a grant the from the New York Community Trust. 


\section{References}

[1] A.M.Sanchez, P.R.Montero, Simplifying Data Fitting using Branching Ratios as Constraints in Alpha Spectrometry, Nucl.Instrum.Methods Phys.Res. A420, 481 (1999)

[2] A.Lorenz, Decay Data of the Transactinium Nuclides , IAEA Tech.Rept.Ser., No.261, 1986.

[3] S.A.Woods, D.H.Woods, M.J.Woods, S.M.Jerome, M.Burke, N.E.Bowles, S.E.M.Lucas, C.Paton Walsh, Standardization and Measurement of the Decay Scheme Data of ${ }^{243} \mathrm{Am}$ and ${ }^{239} \mathrm{~Np}$, Nucl.Instrum.Methods Phys.Res. A369, 1996, p. 472.

[4] D.Sardari, T.D.Mac Mahon, S.P.Holloway, ${ }^{239}$ U and ${ }^{243}$ Am Decay Data, Nucl.Instrum.Methods Phys.Res. A369, 1996, p. 486.

[5] G.T.Ewan, J.S.Geiger, R.L.Graham, D.R.MacKenzie, Conversion Electron Spectrum of Np ${ }^{239}$ and Level Scheme of $\mathrm{Pu}^{239}$, Phys.Rev. 116, 1959, p. 950.

[6] A.M.Sanchez, P.R.Montero, Simplifying Data Fitting using Branching Ratios as Constraints in Alpha Spectrometry, Nucl.Instrum.Methods Phys.Res. A420, 1999, p. 481.

[7] J.J. Dufour, J.H. Foos, X.J.C Dufour, Formation and Properties of Hydrex and Deutex, Conf. Proce. Vol 64, Anomalies in Hydrogen/Deuterium Loaded Metals, S.I.F., Bologna, 1999, p. 29.

[8] H. Kozima, K. Arai, Local Coherence, Condensation and Nuclear Reaction of Neutrons at Crystal Boundary of Metal Hydrides and Deuterides, Int. J. Hydrogen Energy 25 (9), 2000, p. 845.

[9] J. Dash, I. Savvatimova, S. Frantz, E. Weis, and H. Kozima, Effects of Glow Discharge with Hydrogen Isotope Plasmas on Radioactivity of Uranium, Proc. of the $9^{\text {th }}$ International Conference on Cold Fusion, Beijing, p. 77, 2002.

[10] J. Dash, I. Savvatimova, S. Frantz, E. Weis, Effects of Glow Discharge with Hydrogen Isotope Plasmas on Radioactivity of Uranium, submitted for publication. 